\title{
POR QUE ESCOLHI FAZER UM CURSO DE LICENCIATURA? PERFIL E MOTIVAÇÃO DOS INGRESSANTES DA UNESP
}

\author{
Amadeu Moura Bego ${ }^{\mathrm{a}, *}$ e Tarso Bortolucci Ferrari ${ }^{\mathrm{b}}$ \\ aDepartamento de Química Geral e Inorgânica, Instituto de Química, Universidade Estadual Paulista “Júlio de Mesquita Filho”, \\ 14800-060 Araraquara - SP, Brasil \\ 'Faculdade de Ciências, Universidade Estadual Paulista "Júlio de Mesquita Filho”, 17033-360 Bauru - SP, Brasil
}

Recebido em 03/08/2017; aceito em 05/10/2017; publicado na web em 28/11/2017

\begin{abstract}
WHY DO I CHOOSE TO DO A "LICENCIATURA IN CHEMISTRY" COURSE? UNESP FRESHMAN PROFILE AND MOTIVATIONS. The present work aims to investigate the profile and motivation that led students to enroll in the undergraduate chemistry courses of the four São Paulo State University campuses. Case studies were carried out at each of the campuses and a comparative study was carried out in order to outline the theme in question. The quantitative data was analyzed by descriptive statistics and the qualitative data was analyzed by Content Analysis. It was found that the majority of the students are female aged between 17 and 19 years and came from public schools; they do not have jobs, and they are at an intermediate socioeconomic level. The vast majority of students chose the undergraduate degree in chemistry because of their interest in the large field of knowledge, along with the reputation and prestige of the university. It has also been identified that the graduates are led to teaching careers for essentially intrinsic motivations based on altruistic values; however, the majority does not choose to pursue a career in basic education. Faced with the scenario of possible "teacher blackout" in High Schools, these findings claim an urgent public educational policy that promotes an effective valuation of the teaching profession in Brazil.
\end{abstract}

Keywords: pre-service teacher education; motivation for teaching; teaching career attractiveness.

\section{INTRODUÇÃO}

Dados relativos a um dos últimos levantamentos realizados pelo Ministério da Educação (MEC) nos mostram que apenas 53,7\% dos professores de química da rede pública de ensino na Educação Básica (EB) possuem a formação específica em licenciatura em química (LQ). ${ }^{1}$ Esses dados vão de encontro ao previsto no artigo 62 da Lei de Diretrizes e Bases da Educação Nacional que fixa como exigência o diploma de licenciatura na área de sua atuação como formação mínima para um professor lecionar na EB. ${ }^{2}$

De modo geral, a literatura acadêmico-científica vem apontando os aspectos que têm afastado os licenciandos da atuação como professor nas redes escolares públicas da EB, dentre os quais podemos citar a desvalorização social do papel do professor e as péssimas condições de trabalho tanto em termos de infraestrutura quanto salariais e de planos de carreira. ${ }^{3-5}$ Essas características citadas também têm incidido nas altas taxas de evasão dos cursos de licenciatura em todo país. ${ }^{5,6}$

Diante da realidade apontada, os problemas que se relacionam à atratividade da carreira docente para atuação na EB têm sido objeto de investigação de diversos trabalhos. Damasceno e colaboradores, ${ }^{3}$ ao abordarem a formação de professores de química na rede escolar pública de Goiás, mostram que entre 2003 e 2007 houve um aumento de 3 para $15 \%$ no número de docentes licenciados em química atuantes na EB. Esse aumento foi considerado insignificante pelos autores, em função do aumento considerável no número de cursos de LQ no mesmo período. Como considerações acerca desse quadro, os autores afirmam que parte dos recém-licenciados acaba migrando para outras atividades com melhores condições de trabalho e de salário.

Sá e Santos, ${ }^{5}$ ao abordarem as motivações para a carreira docente de licenciandos em química de uma universidade pública da Bahia no ano de 2010, identificaram três categorias que emergem dos discursos dos ingressantes - desvio bacharelizante da formação, estímulo do

*e-mail: amadeu@iq.unesp.br campo pedagógico e dicotomia discurso-ação dos formadores. Como resultado da análise do curso baiano, os autores apontam que a maioria dos alunos ingressa no curso de LQ por falta de outras oportunidades, o que acaba por favorecer o desvio do licenciado para outras áreas. Outro aspecto apontado se refere à pequena parcela de estudantes que ingressaram no curso exclusivamente para serem professores. Todavia, um fator da pesquisa muito interessante relaciona-se à identificação de uma parcela significativa de ingressantes que não possuíam o intuito de serem professores, mas afirmaram se sentirem motivados ao exercício da profissão em função da influência positiva por parte de alguns docentes formadores, sobretudo de profissionais que atuam na área de ensino. Fato que, segundo os autores, pode ter impacto importante na reversão do quadro de desvio bacharelizante do curso e da migração dos licenciados para outras carreiras que não a de professor da EB.

Outro aspecto de alta relevância em relação à atratividade da docência se refere às motivações pela procura dos cursos de licenciatura, uma vez que pode revelar os principais fatores acerca da valoração social da carreira de professor em nosso país.

De acordo com Santos e Antunes, ${ }^{7}$ a motivação é um processo que orienta o ser humano a uma determinada ação, a qual pauta-se em um objetivo ou uma meta a ser alcançada. Pela inserção do ser humano no meio social, pode-se considerar que a motivação não parte apenas de princípios intrapessoais, mas também que o envolvimento com outras pessoas pode despertar novas metas e atitudes, ou seja, a motivação também é influenciada por fatores interpessoais. Por isso, a compreensão de processos motivacionais revela-se complexo e multifacetado, pois decorrem da integração de elementos inerentes ao próprio sujeito e também externos a ele. Com isso, Santos e Antunes afirmam que "a motivação do ser humano deve ser entendida na sua integralidade, mas percebida desde sua singularidade", ${ }^{7}$ isto é, o singular de cada pessoa é despertado tanto pela diversidade de fatores subjetivos como também pela diversidade contextual em que a mesma se insere. 
A motivação, portanto, pode ser teoricamente categorizada a partir de fatores intrínsecos e de fatores extrínsecos. A motivação intrínseca se relaciona essencialmente ao interesse individual e, por isso, pressupõe-se que surja de maneira espontânea no sujeito. Nesse sentido, Santos e Antunes afirmam que a atividade motivadora se torna um fim em si mesma. ${ }^{7}$ Já uma pessoa extrinsecamente motivada é aquela que executa uma tarefa por motivos de compensações externas que podem ser, por exemplo, de ordem social. Cabe salientar que, segundo os autores, os motivos sociais possuem grande influência na ação dos indivíduos. Diante disso, as motivações intrínsecas e extrínsecas se inter-relacionam e interatuam constantemente no processo motivacional de um indivíduo. Uma motivação extrínseca pode se revelar em uma nova motivação internalizada no sujeito, alterando ou se sobressaindo a uma motivação intrínseca.

No contexto motivacional durante a formação inicial de professores de química para atuações na $\mathrm{EB}$, algumas pesquisas nos mostram que as motivações intrínsecas se estendem no campo de valores altruístas referentes à profissão docente,${ }^{3-5}$ como a predisposição ao ensino, a opção por querer mudar o mundo e a opção por gostar de crianças. Todas essas motivações se relacionam com o professor em formação em relação a seu autoconceito, a sua identificação pessoal com a profissão, a seus interesses e habilidades, a sua maturidade e seus valores pessoais. Por isso, essas motivações estão atreladas às características da personalidade da pessoa.

Já as motivações extrínsecas que despertam ou não os licenciandos ao exercício da docência são, principalmente, influenciadas por aspectos de ordem socioeconômica que abrangem questões relativas a perspectivas de emprego e renda e à taxa de retorno da profissão e seu prestígio social. Entretanto, cabe dizer que, dependendo do nível socioeconômico do estudante, esse fator pode influenciar de maneira distinta na escolha pela carreira docente, como mostrado no trabalho de Gatti e colaboradores. ${ }^{8}$ De acordo com os autores, estudantes de nível socioeconômico mais baixo tendem a encarar as condições salariais da profissão docente como possibilidade de ascensão social ao contrário dos estudantes de nível socioeconômico mais elevado. Outros aspectos como o estímulo por meio dos discursos dos professores formadores e os componentes curriculares dos cursos de licenciaturas também podem influenciar na escolha pela profissão. ${ }^{5}$

Diante dessa temática, vale ressaltar que, já em 2007, o relatório produzido pela Comissão Especial instituída no âmbito da Câmara de Educação Básica (CEB) do Conselho Nacional de Educação (CNE) para estudar medidas que visassem a superar o déficit docente no Ensino Médio (EM), alertou que, caso medidas emergenciais e estruturais não fossem tomadas, o Brasil estaria ameaçado a sofrer um "apagão docente no EM", sobretudo nas áreas de ciências exatas e da natureza. O relatório apresentado pelo MEC apontou que havia uma necessidade no país de cerca de 235 mil professores para o EM, dos quais $10 \%$ somente para a área de Química. ${ }^{9}$ Todavia, em que pese a relevância do tema e de seu quadro emergencial, Gatti e colaboradores afirmam que, ${ }^{8}$ no Brasil, a questão da atratividade da carreira docente não tem sido alvo de sistemáticas pesquisas acadêmico-científicas. Isso corrobora a afirmação de Sá e Santos de que investigações similares às conduzidas por eles seriam muito importantes em função de possibilitar um panorama empírico-analítico mais amplo das particularidades que determinam a carência de professores de química em diferentes locais e dos problemas generalizados que dizem respeito a essa carência em todo o país, ${ }^{5}$ objetivando contribuir para a implementação de políticas públicas que reduzam esses problemas de atratividade.

Nesse sentido, temos realizado nos últimos anos investigações sobre as motivações dos ingressantes nos quatro diferentes cursos de LQ da Universidade Estadual Paulista "Júlio de Mesquita Filho" (Unesp). Essas investigações foram conduzidas por meio de estudos de caso nos campi de Araraquara, Bauru, Presidente Prudente e São José do Rio Preto. ${ }^{10-14}$ Como decorrência dessas investigações, o objetivo desse trabalho é analisar aproximações e afastamentos entre as motivações que conduziram os estudantes a ingressarem nos diferentes cursos de LQ da Unesp, a fim de traçar um panorama da temática em questão em relação a uma das três mais importantes universidades estaduais públicas paulistas.

\section{COLETA DE INFORMAÇÕES E ANÁLISE DOS DADOS}

\section{Caracterização dos cursos de química da Unesp}

Nessa seção apresenta-se as principais características dos quatro cursos de LQ da Unesp. O curso de LQ do Instituto de Química da Unesp - campus de Araraquara (IQ/CAr) - é o mais antigo, tendo iniciado suas turmas em 1991 nos moldes do parecer do Conselho Federal de Educação (CFE 297/62) com duração de 5 anos e oferecendo anualmente 30 vagas no período noturno. Até 2006, o Projeto Pedagógico de Curso (PPC) em Araraquara era o mesmo para as modalidades de Bacharelado em Química e LQ. ${ }^{15}$ A mudança no PPC de 2006 decorreu das exigências para as "Diretrizes Curriculares Nacionais para a Formação de Professores da Educação Básica, em nível superior, curso de Licenciatura de graduação plena”, segundo parecer do Conselho Nacional da Educação CNE/CP 01/2002. ${ }^{16}$ De acordo com o PPC, o licenciado formado pelo IQ/CAr pode lecionar a disciplina de Química no EM e no ensino fundamental (EF), além de poder atuar no setor produtivo exercendo as mesmas atividades que um bacharel em Química.

O curso de graduação em LQ da Faculdade de Ciências (FC) da Unesp, campus Bauru, foi implementado no ano de 2002. Em 2012 o curso foi reestruturado, passando a oferecer Licenciatura em Química e Bacharelado em Química Ambiental Tecnológica. Tal mudança foi justificada no PPC como uma forma de formar profissionais qualificados com uma "ampla e sólida base conceitual na área de química e nas especificidades" das modalidades oferecidas. ${ }^{17} \mathrm{O}$ tempo de duração do curso é de 5 anos e são oferecidas 40 vagas no período noturno. A entrada para o vestibular em ambas as modalidades - licenciatura e bacharelado - é única e os alunos cursam as disciplinas comuns até o fim do segundo ano do curso, podendo posteriormente, optar pela dupla habilitação ou por apenas uma das duas modalidades oferecidas. Segundo o PPC, o licenciado formado pode lecionar a disciplina de Química no EF e EM e também atuar no setor produtivo junto às empresas do ramo químico. O PPC está em congruência às exigências da Resolução CNE/CP 1/2002.

Na Faculdade de Ciências e Tecnologia (FCT) da Unesp, campus Presidente Prudente, o curso de LQ foi implementado em 2003 com duração de 5 anos, oferecendo 40 vagas anuais no período noturno. O licenciado formado na FCT pode lecionar a disciplina de Química no EM e pode atuar também no setor produtivo em empresas de ramo químico, assim como um bacharel em Química. ${ }^{18} \mathrm{~A}$ competência formal explicitada no PPC para dar crédito à atuação no ramo químico ao profissional licenciado é a Resolução Normativa do Conselho Federal de Química (CFQ) no 36 de 25/04/1974 que confere atribuições aos profissionais de química elencando atividades aos profissionais da modalidade de licenciatura. O PPC não deixou explícito a data de sua implementação, apenas a data de publicação da Resolução Unesp de novembro de 2007, que aprovou a estrutura curricular do curso. Além disso, o PPC também não citou as resoluções e deliberações do CNE e CEE as quais deveria estar fundamentado.

O curso de Bacharelado em Química Ambiental da Unesp de São José do Rio Preto foi implementado em 2003, tendo sido reestruturado no ano de 2012 e passando a receber o nome de curso de Graduação em Química com as modalidades de Bacharelado em Química 
Ambiental e LQ. A forma de ingresso no vestibular é unificada, sendo que somente no segundo ano do curso os discentes optam pela modalidade que desejam cursar. O tempo de duração do curso é de 4 anos, sendo oferecidas 50 vagas anuais no período diurno. De acordo com o PPC, os formados na modalidade de licenciatura podem optar tanto por trabalhar na área de ensino na EB como químicos na área ambiental. ${ }^{19} \mathrm{O}$ PPC é comum para os cursos de bacharelado e licenciatura atendendo às resoluções CNE/CP 9/2001 e CNE/CP 2/2002.

\section{Procedimentos metodológicos}

Considerando os diferentes cursos e o contexto desta pesquisa, definiu-se como problema a seguinte questão: quais as aproximações $e$ afastamentos entre as motivações que conduziram estudantes a ingressarem nos diferentes cursos de licenciatura em química da Unesp?

Como desdobramento da questão central e de forma a operacionalizar o processo de coleta e tratamento de informações, propôs-se as seguintes questões de pesquisa: i) que fatores foram responsáveis pela escolha da Universidade e como se relacionam com o nível socioeconômico dos ingressantes?; ii) que fatores foram responsáveis pela escolha do curso?; iii) quais as expectativas dos licenciandos acerca de suas carreiras profissionais?; iv) qual a percepção dos licenciandos acerca da profissão docente?

Para a consecução desses objetivos, realizou-se uma pesquisa empírica não-experimental e de caráter qualiquantitativo a fim de se interpretar determinada realidade social, porém sem a realização de manipulação e o isolamento de variáveis experimentais..$^{20}$ Os dados quantitativos foram tratados por meio dos princípios da estatística descritiva e permitiram a organização dos gráficos e tabelas acerca do perfil dos graduandos no ano de 2013. ${ }^{21}$ Para a análise de dados qualitativos junto aos questionários em cada um dos estudos de caso foram utilizados os procedimentos da Análise de Conteúdo propostos por Bardin. ${ }^{22}$

Os primeiros dados coletados em 2013 resultaram em estudos de cada um dos casos separadamente, sendo estes apresentados na forma de diversos trabalhos em congressos da área até o ano de $2016 .{ }^{10-14} \mathrm{~A}$ presente investigação é, portanto, decorrente dos estudos anteriores, buscando o confronto dos dados obtidos em cada um dos casos a fim de analisar suas aproximações e afastamentos.

Flick, ${ }^{23}$ ao abordar os desenhos básicos de uma pesquisa, apresenta as diferenças entre um estudo de caso e um estudo comparativo. Para o autor, no estudo de caso, a questão mais relevante consiste em definir o caso e seus limitantes, os quais são guiados pelo problema de pesquisa e suas respectivas questões. Já no estudo comparativo o autor afirma que as questões mais relevantes se referem à definição da dimensão da comparação e a como o pesquisador levará em consideração o contexto dos casos no estudo que irá realizar.

A partir dessas considerações, essa pesquisa tem o desenho de um "Estudo Comparativo" de diferentes casos, quais sejam, as motivações dos estudantes nos quatros diferentes cursos de LQ da Unesp. Esse estudo comparativo decorre do levantamento de informações obtidas por meio do questionário elaborado por Sgarbosa e colaboradores. ${ }^{14}$ O questionário apresenta 36 itens divididos em 3 grandes blocos de investigação. O primeiro bloco contém questões que permitiram a caracterização dos ingressantes e de seu nível socioeconômico (NSE). O segundo bloco visava levantar informações acerca dos principais fatores que influenciaram os estudantes a ingressarem nos diferentes cursos de LQ na Unesp. Por fim, o terceiro bloco objetivava coletar informações sobre as expectativas dos licenciandos para atuarem na carreira docente e também suas percepções sobre o trabalho do professor no tocante a sua importância social e a sua valorização profissional.
No total, 139 estudantes responderam ao questionário no segundo semestre do ano de 2013. Com exceção do campus de S. J. do Rio Preto, todos os estudantes que responderam ao questionário estavam no primeiro ano do curso. Em S. J. do Rio Preto, os respondentes eram alunos do segundo ano, representando 47 alunos no total, os quais 18 ainda não haviam optado pela modalidade, 20 optaram pela modalidade de Bacharelado em Química Ambiental e somente 9 haviam optado pela modalidade de LQ. Cabe sublinhar que somente os alunos (9) que optaram pela modalidade de LQ no curso de S. J. do Rio Preto foram considerados nesta pesquisa, além disso não foi realizada a aplicação do questionário aos alunos que deveriam estar no $3^{\circ}$ ano do curso de Bauru e optado pela LQ, pois, obviamente, os alunos ainda não haviam finalizado o $2^{\circ}$ ano. Os campi de Araraquara, Bauru e Presidente Prudente tiveram, respectivamente, 29, 30 e 33 alunos pesquisados. A fim de se respeitar o sigilo e a confidencialidade dos estudantes, realizou-se um processo de anonimização por meio da atribuição de códigos com a(s) letra(s) inicial(is) da cidade acompanhado por uma numeração que variava de acordo com o número de respondentes em cada campus.

\section{RESULTADOS E DISCUSSÃO}

\section{Caracterizando os licenciandos - faixa etária, gênero,} formação básica, atuação profissional e nível socioeconômico

Como pode ser visto nos dados da Tabela 1, a maioria dos licenciandos é do sexo feminino, totalizando 59,4\%. O caso mais expressivo é em S. J. do Rio Preto, já que a quantidade de mulheres que optaram pela modalidade de licenciatura representa $88,9 \%$. A mesma predominância de gênero em cursos de licenciatura foi encontrada na Universidade Estadual de Ponta Grossa (UEPG), na Universidade Federal de Rondônia (UNIR) e na Universidade do Estado da Bahia (UNEB). ${ }^{4,5,24}$

Esses dados indicam um fato bastante interessante concernente à questão da feminização da carreira docente. Em âmbito nacional, para Gatti e colaboradores, esse fato "coloca a questão de gênero em nosso contexto social como um dos fatores intervenientes" "nas motivações e escolhas pela docência. Situação semelhante também se detecta internacional e historicamente. Em sua análise, Montero ressalta que o ensino, ${ }^{25}$ sobretudo os níveis mais baixos da EB, tem sido considerado socialmente como uma atividade (ideal) para as mulheres, por associações às características consideradas femininas - afetividade, sensibilidade, intuição etc. - e pelos papéis exercidos pelas mulheres na vida familiar. Além disso, a pesquisadora alerta sobre a "estreita ligação entre as formas de organização social e o gênero que produziram uma extensa e persistente opressão feminina". ${ }^{25}$ Devido a estas e outras circunstâncias históricas e culturalmente instituídas, pode-se associar a feminização no ensino com a desvalorização remuneratória do trabalho docente e, consequentemente, atratividade dos cursos de licenciatura quando comparada com outros cursos de exatas de maior prestígio social, como, por exemplo, os cursos de engenharia, que são majoritariamente frequentados por homens. ${ }^{26,27}$

Em relação à idade, $59,6 \%$ dos respondentes apontaram ter entre 17 e 19 anos remetendo à constatação de que a maioria teve ingresso imediato no vestibular logo após a conclusão do EM (Tabela 1). O caso do campus de S. J. do Rio Preto, em que a maior parte respondeu ter idade igual ou superior a 20 anos, deve-se ao fato dos entrevistados serem os únicos pesquisados a estarem no segundo ano de graduação.

A Figura 1 mostra, em termos percentuais, a rede de ensino frequentada pelos licenciandos dos quatro campi. Dos respondentes, o número de licenciandos que estudaram integralmente em escolas públicas durante a EB é de $46,5 \%$, enquanto apenas $25,7 \%$ dos alunos estudaram somente em escolas particulares durante a EB. Já o 
Tabela 1. Caracterização dos Licenciandos

\begin{tabular}{|c|c|c|c|c|c|c|c|c|c|}
\hline \multirow{2}{*}{ Característica } & \multirow{2}{*}{ Perfil do aluno } & \multicolumn{8}{|c|}{ Percentual } \\
\hline & & \multicolumn{2}{|c|}{ Araraquara } & \multicolumn{2}{|c|}{ Bauru } & \multicolumn{2}{|c|}{ Presidente Prudente } & \multicolumn{2}{|c|}{ S. J. do Rio Preto } \\
\hline \multirow{2}{*}{ Sexo } & Feminino & \multicolumn{2}{|c|}{51,7} & \multicolumn{2}{|c|}{53,3} & \multicolumn{2}{|c|}{63,6} & \multicolumn{2}{|c|}{88,8} \\
\hline & Masculino & \multicolumn{2}{|c|}{48,3} & \multicolumn{2}{|c|}{46,6} & \multicolumn{2}{|c|}{36,4} & \multicolumn{2}{|c|}{11,2} \\
\hline \multirow{2}{*}{ Idade } & Entre 17 e 19 anos & \multicolumn{2}{|c|}{62,1} & \multicolumn{2}{|c|}{60,0} & \multicolumn{2}{|c|}{67,7} & \multicolumn{2}{|c|}{22,2} \\
\hline & Mais de 20 anos & \multicolumn{2}{|c|}{37,9} & \multicolumn{2}{|c|}{40,0} & \multicolumn{2}{|c|}{32,3} & \multicolumn{2}{|c|}{77,8} \\
\hline \multirow{4}{*}{ Cor declarada } & Branco & \multicolumn{2}{|c|}{75,9} & \multicolumn{2}{|c|}{76,7} & \multicolumn{2}{|c|}{69,7} & \multicolumn{2}{|c|}{66,7} \\
\hline & Negro & & & & & & & & \\
\hline & Amarelo & & & & & & & & \\
\hline & Pardo ou mulato & & & & & & & & \\
\hline & $\operatorname{Sim}$ & & & & & & & & \\
\hline Você trabalha? & Não & & & & & & & & \\
\hline & Por necessidade de ajudar a família & & & & & & & & \\
\hline Por que você & Para ser mais independente & & & & & & & & \\
\hline & Outros motivos & & & & & & & & \\
\hline & 30 horas semanais & & & & & & & & \\
\hline Sua jornada de & 40 horas semanais & & & & & & & & \\
\hline & Superior a 40 horas semanais & & & & & & & & \\
\hline & & Mãe & Pai & Mãe & Pai & Mãe & Pai & Mãe & Pai \\
\hline & Nunca frequentou a escolar & - & 3,4 & - & - & - & 3,2 & - & - \\
\hline & Ensino fundamental incompleto & 27,6 & 6,9 & 6,7 & 16,7 & 12,1 & 9,7 & 11,1 & 22,2 \\
\hline & Ensino fundamental completo & 10,3 & 13,8 & - & 6,7 & 9,1 & 3,2 & 11,1 & 11,1 \\
\hline Escolaridade dos pais & Ensino médio incompleto & 17,2 & 17,2 & 6,7 & 3,3 & 6,7 & 3,2 & - & - \\
\hline & Ensino médio completo & 34,5 & 41,4 & 40,0 & 30,0 & 33,3 & 41,9 & 33,3 & 22,2 \\
\hline & Ensino superior incompleto & - & 3,4 & 13,3 & 13,3 & 12,1 & 6,5 & - & 22,2 \\
\hline & Ensino superior completo & 10,3 & 13,8 & 30,0 & 26,7 & 27,8 & 32,3 & 44,4 & 22,2 \\
\hline & Baixo & 10,3 & & 3,33 & & 18,2 & & 11,1 & \\
\hline NSE & Intermediário & 86,2 & & 60,0 & & 51,5 & & 55,5 & \\
\hline & Alto & 3,5 & & 36,67 & & 30,3 & & 33,3 & \\
\hline
\end{tabular}

restante, ou iniciaram em escolas públicas e mudaram para escolas particulares $(19,8 \%)$ ou iniciaram em escolas particulares e se transferiram para as públicas $(7,9 \%)$. O único campus no qual a maioria não é proveniente da escola pública foi o de Bauru, no qual há mais ingressantes provenientes de escolas particulares. Esse dado vai de encontro ao fato de Bauru possuir o menor índice de NSE baixo, além de possuir o número mais elevado de ingressantes com NSE alto, corroborando o fato de a maioria dos alunos serem provenientes da rede privada de ensino.

Outro fator analisado se refere à inserção dos licenciandos no mercado de trabalho enquanto cursam a faculdade (Tabela 1). No momento da entrevista, um total de 75,2\% dos entrevistados afirmou não trabalhar, fato que mostra uma importante mudança da tendência do perfil dos alunos que ingressam nos cursos de licenciatura das Instituições de Ensino Superior (IES) brasileiras quando comparado com os dados da década de 1990, em que a maioria dos estudantes era formada de trabalhadores. ${ }^{28}$ Inclusive esse perfil de alunos não trabalhadores se mantém nos cursos de LQ noturnos. Em relação ao perfil dos licenciandos que trabalham, a maioria é constituída de alunos provenientes de escolas públicas $(62,5 \%)$ com mais de 20 anos de idade (52\%). Quando questionados do porquê trabalham, do total de entrevistados de todos os campi, 63,6\% afirmaram que exercem suas funções para serem independentes e $27,3 \%$ por necessidades de ajudar a família. Na cidade de Araraquara, prevaleceu a necessidade de se ajudar a família em detrimento da independência financeira, fator este que se liga diretamente ao fato dos alunos serem provenientes de classes menos favorecidas.

Com as informações coletadas, foi construído um indicador de NSE com base nos critérios de pontuação definidos por Gatti

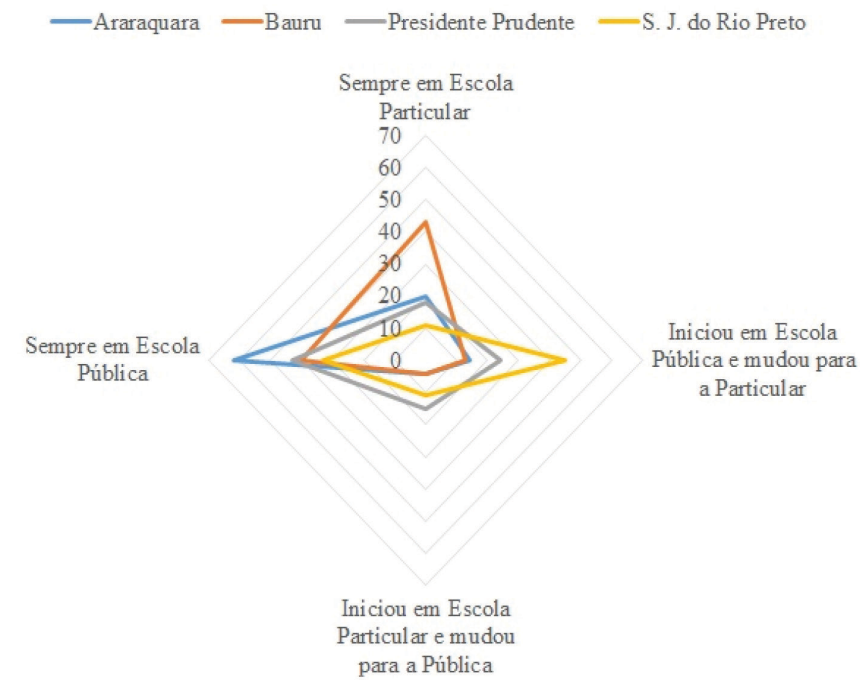

Figura 1. Escolarização básica dos estudantes nos cursos de licenciatura nos diferentes campi (valores em \%)

e colaboradores. ${ }^{8}$ A classificação ocorreu em função da pontuação total atingida por cada entrevistado de acordo com os seguintes intervalos: i) até 10 pontos: NSE baixo; ii) entre 11 e 20 pontos: NSE intermediário; iii) acima de 20 pontos: NSE alto. Como resultado (Tabela 1), percebe-se que a maioria dos licenciandos se enquadra no NSE intermediário, totalizando $64,4 \%$ ante $24,7 \%$ com NSE alto e $10,9 \%$ com NSE baixo. Ao se analisar cada campus separadamente, percebemos que o de Araraquara é o que tem a menor quantidade 
de alunos que se encaixam no NSE alto, sendo apenas 1 dos 29 que responderam o questionário. $\mathrm{O}$ campus com menor quantidade de estudantes com NSE baixo é o de Bauru, com apenas 1 dos 30 ingressantes respondentes.

O fato do número de ingressantes com NSE alto no campus de Araraquara ser distinto dos demais se correlaciona com a escolarização dos pais desses alunos. A partir dos dados da Tabela 1, observa-se que os valores das porcentagens de pais e mães com escolaridade de nível superior se aproxima com os percentuais de alunos com NSE alto dos campi de Bauru, Presidente Prudente e S. J. do Rio Preto, diferindo-se do campus de Araraquara que possui um reduzido valor de pais e mães com grau superior de escolaridade. Já o maior percentual de ingressantes com NSE baixo em Presidente Prudente, aliado ao fato de ser o campus que apresenta o maior índice de trabalhadores dentre os estudantes, pode ser justificado ao se confrontar tais dados com os obtidos junto à Fundação Sistema Estadual de Análise de Dados (SEADE). Esses dados mostram que a região administrativa de Presidente Prudente, dentre as regiões que compõem cada campi aqui estudados, é a que possui o maior percentual de domicílios com famílias com renda per capita de até $1 / 2$ ou $1 / 4$ de salário mínimo, representando $26,4 \%$ da população total, distante 5,2 pontos percentuais da segunda região com pior índice que é a de Bauru.

\section{Motivações dos licenciandos para a escolha acadêmica e expectativas profissionais}

O segundo bloco de questões envolve informações acerca dos principais fatores que influenciaram os estudantes a ingressarem no curso de LQ.

Um número significativo de licenciandos $(65,3 \%)$ dos quatros campi respondeu que se submeteu a outros exames vestibulares além daqueles no qual foram aprovados. O único campus que contribuiu de maneira oposta a este resultado foi o de S. J. do Rio Preto, no qual $66,7 \%$ dos entrevistados afirmaram terem se submetido apenas ao vestibular no qual foram aprovados.

Ao serem questionados sobre se o curso atual havia sido a primeira opção no vestibular, nos campi de Araraquara, Bauru e Presidente Prudente, a média daqueles que afirmam que suas primeiras opções foram cursos de LQ é igual a 77,2\%. Com isso, pode-se inferir que, nos três campi, a maioria dos estudantes que se submeteu a outros exames vestibulares optou por prestar o curso de LQ também em outros vestibulares. Os 26 sujeitos dos quatro campi, que afirmaram não ser o curso atual a primeira opção, apontaram profissões que não se relacionam ao exercício da docência como suas primeiras opções, das quais, em sua maioria, são nas áreas das engenharias. Entretanto, no campus de S. J. do Rio Preto 55,5\% dos discentes afirmaram que o curso de LQ não havia sido a primeira opção (Figura 2). Esse dado é preocupante, pois os respondentes desse campus são alunos do segundo ano do curso que já haviam optado pela modalidade de

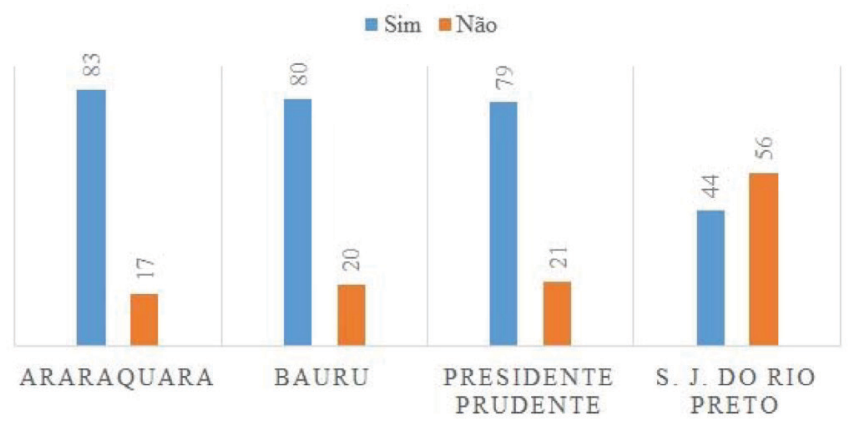

Figura 2. Respostas, em porcentagem, sobre se o curso atual é a primeira opção dos ingressantes licenciatura. Nesse sentido, cabe-nos refletir sobre a escolha da profissão docente como sendo, muitas vezes, a "mais viável", por motivos que perpassam desde o ingresso na Universidade até a inserção no mercado de trabalho. Rabelo expressa essa situação como uma opção pela docência por falta de oportunidade, ${ }^{29}$ na qual os licenciandos são movidos por motivações extrínsecas.

A próxima questão do questionário fornecia algumas opções aos estudantes sobre os principais motivos que os fizeram se matricular no curso, dentre as quais os sujeitos escolheram como resposta, em sua maioria $(68,5 \%)$, o fato de gostarem do curso e pela reputação da universidade. Apenas 14,3\% dos sujeitos afirmaram ter se matriculado no curso atual pelo fato de a universidade ser pública e ser localizada na cidade em que residiam, outros $7,6 \%$ afirmam ter escolhido o curso em função de a universidade ser pública, 3,8\% afirmaram que o curso de química havia sido o único curso em que haviam sido aprovados em universidade pública e 5,7\% assinalaram motivos diversos. Esses dados apontam para a questão de que um fator de grande influência para a escolha do curso de graduação pelos estudantes foi o prestígio das universidades públicas paulistas. De fato, as universidades públicas paulistas gozam de grande reputação social e têm seus cursos amplamente procurados por parcela significativa dos estudantes concluintes do EM, haja vista que, por exemplo, no ano de 2016, a Unesp apresentou seu maior índice histórico de inscritos no exame vestibular. ${ }^{30}$ Esses dados revelam que as motivações dos ingressantes não relacionaram exclusivamente a fatores extrínsecos de ordem socioeconômica, como a necessidade da universidade ser pública e/ ou estar na cidade em que os estudantes residiam.

Quando questionados sobre o que mais influenciou na escolha pelo curso, $88,1 \%$ declararam que decidiram se matricular no curso de química por opiniões próprias e por pretensões profissionais. $5,0 \%$ apontaram que foram influenciados por opiniões de amigos e familiares e outros 2,0\% afirmaram que a opinião dos pais foi o que mais influenciou para a matrícula no curso. $5 \%$ dos sujeitos declaram motivos diversos.

Em outra questão foi solicitado que os respondentes apontassem se sabiam a diferença profissional entre um bacharel e um licenciado em química e que especificassem as atribuições profissionais das duas carreiras. Três categorias foram levantadas a partir da análise das respostas obtidas pelos pesquisadores, sendo estas: sabe a diferença, sabe parcialmente a diferença e não sabe ou não justificou. A Figura 3 mostra os resultados obtidos para cada campus.
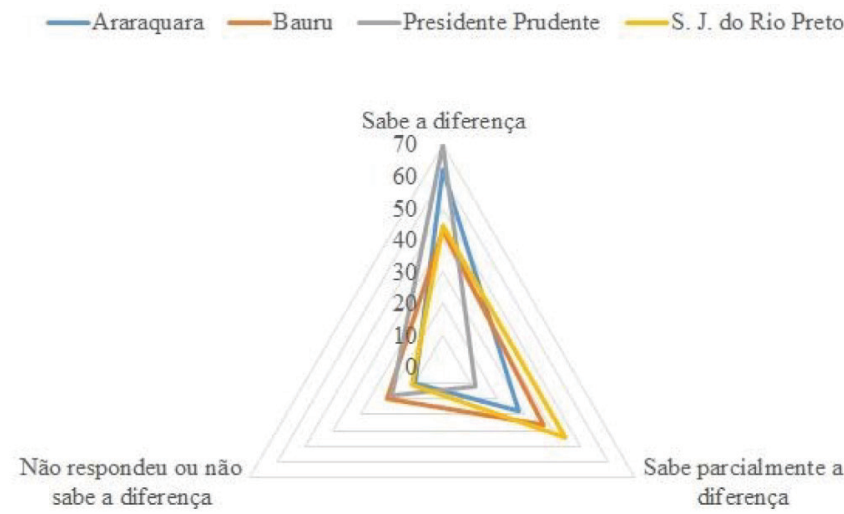

Figura 3. Classificação das respostas, em porcentagem, sobre a diferença entre as atribuições de um bacharelado e de um licenciado

Observou-se, nessa questão, que os licenciandos que estudam nas cidades de Araraquara e de Presidente Prudente possuem maior discernimento quanto à diferença de atribuições entre um licenciado e um bacharel, pois em ambos os campi a porcentagem destes 
representou mais do que $60 \%$. Já nos campi de Bauru e S. J. do Rio Preto, $43,0 \%$ e 44,4\% sabiam a diferença e $37,0 \%$ e 44,4\% sabiam parcialmente a diferença, respectivamente, entre as duas modalidades de curso. Esse fato pode estar ligado à forma de ingresso unificada em ambos os campi em que os vestibulandos poderiam estar menos atentos a essas diferenças. Esse fato reclama ações mais específicas e eficazes da Unesp no tocante à divulgação de seu exame vestibular e de seus cursos e modalidades. Contudo, pode-se afirmar que a maioria dos estudantes dos quatro campi optou por se matricular no curso de química com certa consciência sobre as atribuições profissionais de um licenciado e de um bacharel.

Conforme dados apresentados na Figura 4, a maior incidência de respostas dos estudantes dos quatro campi foi ter escolhido um curso de licenciatura por quererem ser professores. Araraquara apresentou a maior porcentagem (55\%), seguida de S. J. do Rio Preto $(44,4 \%)$, de Presidente Prudente $(33,3 \%)$ e de Bauru (30\%). As outras respostas se enquadram no fato do curso ser noturno, por possuir menor relação candidato/vaga, pela dupla habilitação licenciado/bacharel ou pelo fato da cidade não oferecer curso de bacharelado em química, como é o caso de Presidente Prudente. O resultado obtido se distancia do que foi observado na UEPG, ${ }^{4}$ onde mais de $53 \%$ dos licenciandos apontaram ter escolhido licenciatura em função do fato de o curso ser noturno.

\section{-Araraquara —Bauru —Presidente Prudente —S. J. do Rio Preto}

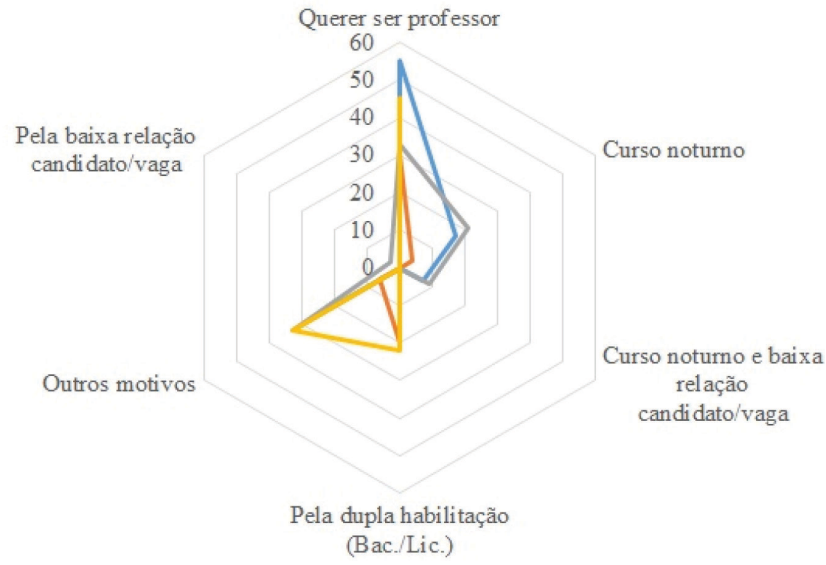

Figura 4. Categoria das respostas, em termos percentuais, sobre o porquê de ingressarem em licenciatura em química

Além de serem questionados sobre os motivos para terem entrando na licenciatura, os estudantes foram questionados especificamente se, uma vez matriculados no curso, pensavam em ser professores. De modo surpreendente, $100 \% ; 89,7 \%$; 83,7\%; 81,8\% dos estudantes de S. J. do Rio Preto, Araraquara, Bauru e Presidente Prudente afirmaram, respectivamente, que pensavam em ser professores. Esse aumento expressivo em relação aos dados apresentados na Figura 4, pode estar associado, por um lado, ao fato de que, assim como afirmam Milaré e Weinert, ${ }^{4}$ o desejo de ser professor não é o principal motivo da escolha pela licenciatura, mas uma vez ingressos, a carreira docente se torna uma possibilidade a ser considerada entre os graduandos; por outro lado, pelo motivo de, como mostrado na Figura 5, os estudantes começarem a pretender atuar em outros níveis de ensino.

É interessante notar na Figura 5 que, com exceção de Araraquara, a maioria absoluta dos estudantes, que afirmou pretender ser professor, não tem pretensão de atuar exclusivamente na EB. A maior parte das respostas estão associadas à possibilidade de atuar como professor no Ensino Superior (ES), representando 26,7\% das intenções. Além disso, considerando-se toda a gama de respostas e somando-as, o

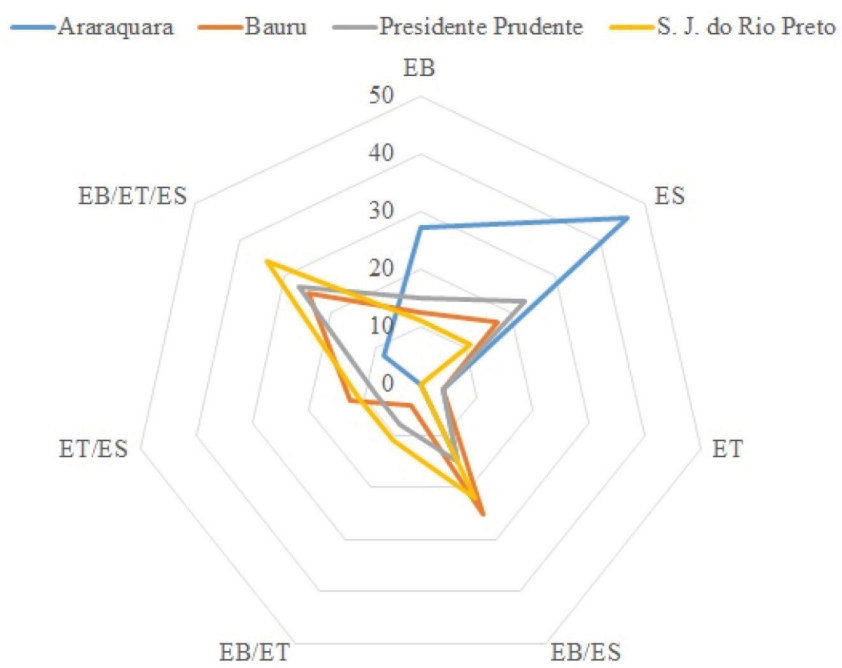

Figura 5. Categorias de respostas, em termos percentuais, sobre em qual nível de ensino o licenciando pretende atuar como professor

ES apareceu em 73,2\% das opções. Sobejamente, esse fato deve-se às melhores condições de trabalho que se tem no ES diante da EB como, por exemplo, infraestrutura, salário e plano de carreira. Os autores Lüdke e Boing ressaltam que o processo de declínio do status da profissão docente na EB tem relação direta com a questão salarial e que esse desprestígio econômico gera, ${ }^{31}$ consequentemente, a diminuição da atratividade da carreira. Ao contrário do trabalho de Gatti e colaboradores, ${ }^{8}$ em que para muitos estudantes de baixo NSE a profissão docente na EB poderia representar ascensão social, o grupo de discentes investigados nessa pesquisa veem a possibilidade de ascensão social relacionada à atuação no ES ou ET e não exclusivamente na EB.

Depois de questionados sobre o nível de ensino que gostariam de atuar, os sujeitos que afirmaram querer ser professores de química responderam a uma questão sobre quais seriam as razões para tal escolha. Por meio de análise de conteúdo das respostas dissertativas, foram obtidas cinco categorias de respostas, conforme apresentado no Quadro 1.

A partir dos resultados, percebe-se uma forte tendência nos quatro campi voltada à Categoria III, a qual representa respostas que se encaixam em valores altruístas, vocação e realização pessoal, representando, na média, pouco mais de $75 \%$ do total de respostas. Nessa categoria o ofício de professor está relacionado à ideia de sacerdócio e missão e não ao status de profissão, em que o sentimento de prazer e cumprimento de um dever moral, resultante do ato de ensinar ao próximo, acabaria, de algum modo, por compensar as adversidades encontradas no exercício do magistério, revelando certo grau de altruísmo para o ofício. Essa visão romantizada do ofício de professor, na qual o prazer pessoal é mais relevante do que as desvantagens, também foi identificada por Gatti e colaboradores. ${ }^{8}$ De acordo com os pesquisadores, para essa concepção "pode-se lançar a hipótese de que os alunos enxergam a docência não como profissão, mas como sacerdócio, uma missão em resposta a uma vocação".

A Categoria IV foi a segunda mais frequente, cerca de $20 \%$ do total de respostas, e se refere às expectativas de emprego dos alunos. Percebe-se nessa categoria respostas que não destacam a valorização do profissional, mas sim o fato de ser um ofício que oportuniza os recém-formados a conquistarem empregos com maior facilidade devido à baixa procura e ao baixo número de trabalhadores na área. Em seu trabalho, Gatti e colaboradores destacam uma pesquisa que apontou uma possível explicação para a docência ter atraído mais mulheres do que homens. ${ }^{8}$ Segundo os pesquisadores, os homens, nas decisões ocupacionais, são mais sensíveis à possibilidade de 
Quadro 1. Categorias de respostas referentes à razão para ser professor de química

\begin{tabular}{|c|c|c|c|}
\hline CATEGORIA & CIDADE & CONTAGEM & ESTRATO REPRESENTATIVO \\
\hline \multirow{4}{*}{$\begin{array}{l}\text { I - Interesse e/ou } \\
\text { afinidade com a } \\
\text { grande área }\end{array}$} & Araraquara & $\mathrm{A} 2, \mathrm{~A} 4$ & \multirow{4}{*}{$\begin{array}{l}\text { "Faço iniciação e gosto da área" (A4). } \\
\text { "Ser professor não é a primeira opção, porém minha razão em } \\
\text { pensar em dar aula, é o fato de amar tudo que aprendo com } \\
\text { a química e querer fazer com que outras pessoas tenham a } \\
\text { oportunidade de adquirir esse conhecimento" (B14). }\end{array}$} \\
\hline & Bauru & B14, B23 & \\
\hline & Presidente Prudente & PP8 & \\
\hline & S. J. do Rio Preto & RP1, RP5 & \\
\hline \multirow{4}{*}{$\begin{array}{l}\text { II - Influências de } \\
\text { terceiros }\end{array}$} & Araraquara & - & \multirow{4}{*}{$\begin{array}{l}\text { "Pois os meus professores me influenciaram, mostraram-me } \\
\text { que ser professor é mais do que ensinar uma matéria, um pro- } \\
\text { fessor auxilia na formação educacional, tem influência direta } \\
\text { sobre os alunos, etc." (B7). } \\
\text { "O buscar pelo saber e a opção de poder passar o conheci- } \\
\text { mento para as pessoas é importante para mim e a influência de } \\
\quad \text { ver meus pais trabalhando na área" (PP22). }\end{array}$} \\
\hline & Bauru & B7, B19 & \\
\hline & Presidente Prudente & PP22 & \\
\hline & S. J. do Rio Preto & RP3, RP9 & \\
\hline \multirow{4}{*}{$\begin{array}{l}\text { III - Valores altruístas, } \\
\text { vocação e realização } \\
\text { pessoal }\end{array}$} & Araraquara & $\begin{array}{c}\text { A1, A2, A3, A5, A6, A7, A9, A10, } \\
\text { A11, A12, A13, A15, A16, A17, A18, } \\
\text { A19, A20, A23, A26, A27, A28, A29 }\end{array}$ & \multirow{4}{*}{$\begin{array}{c}\text { "Eu não tenho foco em ser professora. Meu desejo é mais } \\
\text { como uma doação pessoal. As escolas públicas não têm } \\
\text { professores de química, assim, tem muita gente que nunca } \\
\text { teve contato com esse mundo e que por isso não seria capaz de } \\
\text { escolher química. Não sabem se gostam por que não conhe- } \\
\text { cem" (B11). } \\
\text { "A ideia de conseguir passar seus conhecimentos para alguém } \\
\text { e ver que isso poderá ser extremamente importante na vida } \\
\text { dessa pessoa, é uma gratificação que o dinheiro não compra" } \\
\text { (PP1). } \\
\text { "Poder ensinar outras pessoas. Tendo experiências com meus } \\
\text { professores pude chegar à conclusão que o ato de ensinar deve } \\
\text { ser feito com carinho, zelo e por gente que gosta, que tem } \\
\text { paciência. Gostaria de ensinar pessoas igual a mim, mostrando } \\
\text { que o aprender é uma coisa que todos são capazes de fazer" } \\
\text { (RP3). }\end{array}$} \\
\hline & Bauru & $\begin{array}{c}\text { B2, B3, B4, B6, B7, B8, B9, B11, } \\
\text { B13, B14, B16, B18, B19, B20, B21, } \\
\text { B26, B27, B29, B30 }\end{array}$ & \\
\hline & Presidente Prudente & \begin{tabular}{|c|} 
PP1, PP2, PP3, PP8, PP10, PP11, \\
PP12, PP13, PP14, PP16, PP17, PP21, \\
PP22, PP23, PP26, PP28, PP29, PP30, \\
PP31, PP32
\end{tabular} & \\
\hline & S. J. do Rio Preto & RP2, RP3, RP6, RP7, RP8, RP9 & \\
\hline \multirow{4}{*}{$\begin{array}{l}\text { IV - Expectativas de } \\
\text { emprego }\end{array}$} & Araraquara & $\mathrm{A} 8, \mathrm{~A} 11, \mathrm{~A} 24$ & \multirow{4}{*}{$\begin{array}{l}\text { "Independência financeira, oportunidade de emprego logo após } \\
\text { a formação e empatia à profissão" (RP4). } \\
\text { "Devido ao fato de serem poucos os profissionais dessa área na } \\
\text { minha região" (PP9). }\end{array}$} \\
\hline & Bauru & $\mathrm{B} 1, \mathrm{~B} 10, \mathrm{~B} 22$ & \\
\hline & Presidente Prudente & PP7, PP9, PP15, PP27, PP28 & \\
\hline & S. J. do Rio Preto & $\mathrm{RP} 2, \mathrm{RP} 4, \mathrm{RP} 8$ & \\
\hline \multirow{4}{*}{ V - Outros } & Araraquara & $\mathrm{A} 4, \mathrm{~A} 14$ & \multirow{4}{*}{$\begin{array}{c}\text { "Acho uma profissão incrível, mas só exerceria em segunda } \\
\text { opção" (A14). } \\
\text { "Devido à formação universitária para o desenvolvimento de } \\
\text { pesquisas" (B24). }\end{array}$} \\
\hline & Bauru & $\mathrm{B} 10, \mathrm{~B} 11, \mathrm{~B} 14, \mathrm{~B} 15, \mathrm{~B} 24$ & \\
\hline & Presidente Prudente & PP20, PP29 & \\
\hline & S. J. do Rio Preto & - & \\
\hline
\end{tabular}

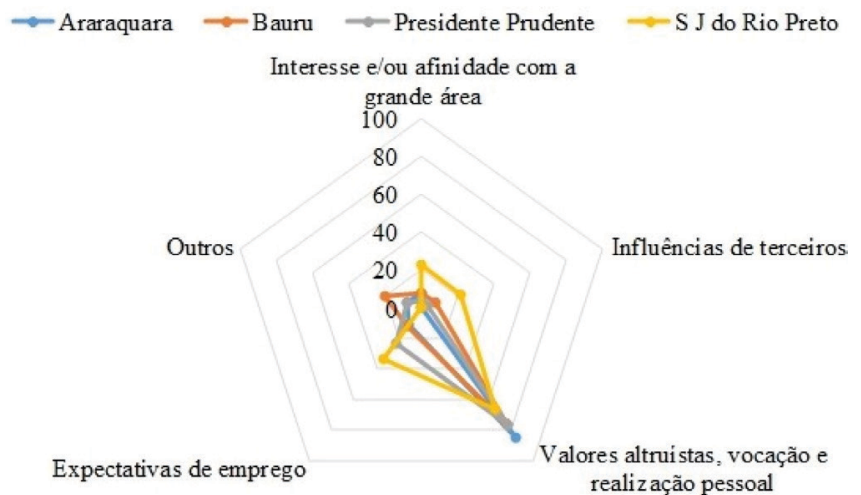

Figura 6. Categorias das respostas, em termos percentuais, referentes à escolha da carreira pelos ingressantes

carreira, enquanto as mulheres são mais influenciadas pela possibilidade de salário imediato. Em concordância com a pesquisa, ao ser analisado o gênero de cada um dos respondentes da Categoria IV, podemos notar que $64,3 \%$ dos que se enquadraram nesse item são do sexo feminino. Além disso, como mostrado na Figura 2, nessa categoria estão a maior parte dos licenciandos do campus de S. J. do
Rio Preto em que o curso de LQ não havia sido a primeira opção. O resultado da pesquisa se torna ainda mais próximo ao se perceber que as respostas que apresentaram os termos "estabilidade", "falta de profissionais na área" e "emprego imediato" foram utilizados por $85,7 \%$ de respondentes do sexo feminino.

Com efeito, a maior parte do grupo de estudantes pesquisado tem motivações intrínsecas em relação ao exercício da docência associadas a valores altruístas e não de status profissional. Por outro lado, um grupo de estudantes apresenta motivações extrínsecas para serem professores, porém essas motivações também não se referem a fatores de status profissional e, sim, de possibilidade de renda imediata.

Posteriormente, foram investigadas as concepções dos ingressantes sobre o trabalho docente. A partir das respostas, foram obtidas cinco categorias apresentadas no Quadro 2.

A partir dos dados do Quadro 2, percebe-se que a maior parte dos ingressantes, $70,3 \%$ do total de respostas, concebem o trabalho docente relacionado a valores altruístas. Logo em seguida, a segunda categoria com maior frequência, $38,6 \%$ das respostas, diz respeito a uma visão do trabalho do professor como desvalorizado profissionalmente e com baixo status social. 20,8\% das respostas se inseriram na Categoria III, a qual aponta o trabalho docente como demasiadamente exaustivo. 
Quadro 2. Categorias de respostas sobre as concepções dos ingressantes acerca do trabalho docente

\begin{tabular}{|c|c|c|c|}
\hline CATEGORIA & CIDADE & CONTAGEM & ESTRATO REPRESENTATIVO \\
\hline \multirow{4}{*}{$\begin{array}{l}\text { I - Desvalorizado } \\
\text { profissionalmente, } \\
\text { profissão de baixo } \\
\quad \text { status social }\end{array}$} & Araraquara & $\begin{array}{c}\text { A2, A3, A4, A6, A7, A11, A14, A16, } \\
\text { A17, A19, A21, A24, A25, A29 }\end{array}$ & \multirow{4}{*}{$\begin{array}{l}\text { "Eu acredito que os professores, sem ser do ensino superior, } \\
\text { são mal remunerados e não têm reconhecimento" (A24). } \\
\text { "Um trabalho de extrema importância para a sociedade, } \\
\text { mas que infelizmente não tem o devido reconhecimento dos } \\
\text { governantes" (B1). } \\
\text { "Vejo desgastado, porém há muitos professores que ainda } \\
\text { demonstram uma grande satisfação e prazer por ensinar. Mas, } \\
\text { os mesmos devem ser valorizados pelos governantes, de modo } \\
\text { que recebam pelo o que merece" (RP9). }\end{array}$} \\
\hline & Bauru & $\begin{array}{c}\text { B1, B2, B10, B12, B14, B18, B20, } \\
\text { B23, B28 }\end{array}$ & \\
\hline & Presidente Prudente & $\begin{array}{l}\text { PP2, PP3, PP5, PP6, PP7, PP10, } \\
\text { PP11, PP15, PP16, PP21, PP24, } \\
\text { PP26, PP28, PP33 }\end{array}$ & \\
\hline & S. J. do Rio Preto & RP5, RP9 & \\
\hline \multirow{4}{*}{$\begin{array}{l}\text { II - Profissão que } \\
\text { oferece recompensa } \\
\text { afetiva pelo bem ao } \\
\text { próximo e de alto grau } \\
\text { de responsabilidade } \\
\text { social }\end{array}$} & Araraquara & $\begin{array}{c}\mathrm{A} 1, \mathrm{~A} 2, \mathrm{~A} 3, \mathrm{~A} 5, \mathrm{~A} 6, \mathrm{~A} 9, \mathrm{~A} 10, \mathrm{~A} 11, \\
\mathrm{~A} 12, \mathrm{~A} 13, \mathrm{~A} 19, \mathrm{~A} 20, \mathrm{~A} 21, \mathrm{~A} 22, \\
\mathrm{~A} 23, \mathrm{~A} 28\end{array}$ & \multirow{4}{*}{$\begin{array}{l}\text { "Possui uma carga horária pesada e uma remuneração baixa, } \\
\text { porém a gratificação pessoal quando se faz os alunos enten- } \\
\text { derem, compensa as desvantagens" (A6). } \\
\text { "Eu vejo que é um cargo muito importante pois o professor } \\
\text { passa os seus conhecimentos aos demais ajudando a construir } \\
\text { uma sociedade melhor" (B5). } \\
\text { "Vejo como um dos trabalhos mais difíceis atualmente. Pois } \\
\text { ser professor consiste em ensinar o próximo, e não é qualquer } \\
\text { um que tem êxito nisso. É uma grande responsabilidade, lidar } \\
\text { com pessoas diferentes que muitas vezes não têm interesse } \\
\text { compartilhar do seu próprio conhecimento e muitas vezes } \\
\text { formar caráter. E, além disso, não é uma profissão valorizada, } \\
\text { mesmo sendo uma das profissões mais importantes" (B12). }\end{array}$} \\
\hline & Bauru & $\begin{array}{c}\text { B1, B2, B3, B4, B5, B6, B8, B11, } \\
\text { B12, B13, B14, B15, B16, B17, } \\
\text { B18, B20, B21, B22, B23, B24, } \\
\text { B25, B26, B28, B29, B30 }\end{array}$ & \\
\hline & Presidente Prudente & $\begin{array}{l}\text { PP1, PP2, PP4, PP5, PP6, PP8, PP9, } \\
\text { PP10, PP11, PP12, PP13, PP14, } \\
\text { PP15, PP16, PP17, PP19, PP20, } \\
\text { PP22, PP24, PP27, PP29, PP30, } \\
\text { PP32, PP33 }\end{array}$ & \\
\hline & S. J. do Rio Preto & RP1, RP2, RP4, RP6, RP7, RP9 & \\
\hline \multirow{4}{*}{ III - Profissão exaustiva } & Araraquara & $\mathrm{A} 4, \mathrm{~A} 6, \mathrm{~A} 10, \mathrm{~A} 15, \mathrm{~A} 22, \mathrm{~A} 27$ & \multirow{4}{*}{$\begin{array}{l}\text { "Um trabalho árduo e mal recompensado muitas vezes" } \\
\text { (B10). } \\
\text { "É muita sobrecarga emocional. Seria bom ser professor por } \\
\text { ajudar alguém, o futuro do país. Mas como a sociedade não } \\
\text { valoriza, acaba sendo algo estressante" (PP11). }\end{array}$} \\
\hline & Bauru & B3, B10, B13, B19, B26 & \\
\hline & Presidente Prudente & PP7, PP11, PP19, PP22, PP28, PP31 & \\
\hline & S. J. do Rio Preto & RP3, RP4, RP5, RP9 & \\
\hline \multirow{4}{*}{ IV - Outros } & Araraquara & $\begin{array}{c}\mathrm{A} 7, \mathrm{~A} 8, \mathrm{~A} 9, \mathrm{~A} 14, \mathrm{~A} 16, \mathrm{~A} 18, \mathrm{~A} 20, \\
\mathrm{~A} 25, \mathrm{~A} 26\end{array}$ & \multirow{4}{*}{$\begin{array}{l}\text { "Inclusão. Essa é a palavra que tenho a dizer de um professor } \\
\text { que tem de saber lidar com todos os tipos de pessoas, situa- } \\
\text { ções e problemas. Esse é o principal trabalho do professor" } \\
\text { (A9). } \\
\text { "É um trabalho complicado. Você tem que aprender além de } \\
\text { ensinar. Aprender a dar aula, aprender a conviver com diferen- } \\
\text { tes tipos de pessoas, adaptar-se a maneiras de ensinar" (RP3). }\end{array}$} \\
\hline & Bauru & B7, B9, B27 & \\
\hline & Presidente Prudente & PP18, PP23, PP25, PP31 & \\
\hline & S. J. do Rio Preto & RP3, RP8 & \\
\hline
\end{tabular}

Adicionalmente, em contraposição à percepção pessoal, no Quadro 3 se encontram as categorias de respostas identificadas para a concepções dos ingressantes acerca da visão da sociedade sobre o trabalho docente.

É bastante interessante notar que a maioria absoluta das respostas se inseriu na categoria em que se acredita que o trabalho do professor não é valorizado, que não há o devido reconhecimento social e profissional e que essa profissão é desrespeitada por pais, alunos, governantes e pela sociedade em geral. Isto é, a maior parte dos licenciandos têm a percepção de que a sociedade vê o trabalho docente como uma profissão desvalorizada e pouco reconhecida. Inclusive em algumas respostas há até uma visão depreciativa do ofício, tais como: "um profissional que não deu certo na vida", "profissionais vistos como coitados e que não deram certo como bacharel", "além de ser uma profissão que serve de 'bico"'.

Nessa perspectiva, os estudantes foram questionados também sobre como seus pais reagiriam caso eles, após formados, decidissem exercer a profissão de professor. Para $54,4 \%$ dos alunos, seus pais apoiariam a decisão. Para 23,8\% dos respondentes, os pais iriam reagir negativamente e, para os $21,8 \%$ restantes, seus pais reagiriam com neutralidade quanto a suas escolhas profissionais. Dentre as justificativas, pode-se citar o fato de terem um membro da família exercendo atividade docente, que contribuiu para a aprovação, como afirma a aluna A23: "Minha família apoiou, pois minha mãe, por exemplo, é professora e ama o que faz". Outra resposta que se destaca é da aluna A21: "Todos me apoiariam grandemente, pois trata-se de uma área em que a satisfação pessoal conta muito mais do que a financeira (no Brasil)". Para ela a docência está relacionada, acima de tudo, à satisfação pessoal que compensa as adversidades vivenciadas na profissão. Nota-se aqui, novamente, o altruísmo identificado anteriormente na percepção dos licenciandos acerca do trabalho docente.

Por fim, de modo a se investigar o que os licenciandos pensavam sobre o salário dos professores, uma das questões informava o piso salarial nacional definido em lei para o ano de 2014 para os professores da EB na rede pública - no qual o salário base passaria para $\mathrm{R} \$$ $2.135,64$ - e solicitava que os estudantes discutissem se esse valor era bom e motivador para o início de carreira ou ruim e desestimulante. ${ }^{32}$ Mais de $60 \%$ dos respondentes afirmaram que consideravam esse salário como sendo um valor baixo e desestimulante para o ingresso na carreira. Massivamente, o campus de Araraquara contribuiu com 
Quadro 3. Categorias de respostas que evidenciam a percepção dos licenciandos acerca da visão da sociedade sobre o trabalho docente

\begin{tabular}{|c|c|c|c|}
\hline CATEGORIA & CIDADE & CONTAGEM & ESTRATO REPRESENTATIVO \\
\hline \multirow{4}{*}{$\begin{array}{l}\text { I - Uma profissão } \\
\text { desvalorizada e pouco } \\
\text { reconhecida }\end{array}$} & Araraquara & $\begin{array}{l}\text { A1, A2, A3, A4, A5 A6, A7, A8, A9, } \\
\text { A10, A11, A12, A13, A14, A15, A17, } \\
\text { A18, A19, A20, A21, A22, A23, A24, } \\
\text { A26, A27, A28, A29 }\end{array}$ & \multirow{4}{*}{$\begin{array}{l}\text { "Sem credibilidade, veem o professor como alguém que não } \\
\text { deu certo na vida é não teve outra opção. “ (A.9) } \\
\text { "Professores de ensino superior me parecem bem vistos. Já } \\
\text { aqueles do ensino fundamental ao médio recebem toda culpa } \\
\text { pelas deficiências do ensino. Apesar de que hoje é bastante } \\
\text { fácil virar professor de escola pública e parece que quem não } \\
\text { tem o que fazer está virando professor. Quem não consegue } \\
\text { desenvolver pesquisa vira professor. E talvez seja por isso } \\
\text { também que está como está. Falo porque tenho muitos amigos } \\
\text { professores. ” (B11) } \\
\text { "Vê com preconceito, primeiro pensa que você é louco por } \\
\text { você escolher química, depois que você é mais louco ainda } \\
\text { por escolher licenciatura. Daí dá para tirar uma ideia. " (PP17) }\end{array}$} \\
\hline & Bauru & $\begin{array}{l}\text { В1, B2, B3, B4, B5, B6, B7, B8, B9, } \\
\text { B10, B11, B12, B13, B14, B16, B17, } \\
\text { B18, B19, B21, B22, B23, B24, B25, } \\
\text { B26, B27, B28, B29, B30 }\end{array}$ & \\
\hline & Presidente Prudente & $\begin{array}{l}\text { PP1, PP2, PP3, PP4 PP5, PP6, PP7, } \\
\text { PP8, PP9, PP10, PP11, PP12, PP13, } \\
\text { PP14, PP15, PP16, PP17, PP19, PP20, } \\
\text { PP21, PP22, PP23, PP24, PP26, PP27, } \\
\text { PP28, PP29, PP31, PP32, PP33 }\end{array}$ & \\
\hline & S. J. do Rio Preto & $\begin{array}{l}\text { RP1, RP2, RP3, RP4, RP5, RP6, RP7, } \\
\text { RP8, RP9 }\end{array}$ & \\
\hline \multirow{4}{*}{$\begin{array}{l}\text { II - Profissão social- } \\
\text { mente importante }\end{array}$} & Araraquara & A10, A14 & \multirow{4}{*}{$\begin{array}{l}\text { "Importante, na verdade, extremamente importante, mas des- } \\
\text { valorizada e desestimulada pelas dificuldades." (A14) } \\
\text { "Acredito que grande parte da sociedade saiba a importância } \\
\text { desse profissional, porém, também veem o professor cada } \\
\text { vez mais desvalorizado. Os profissionais da rede pública são } \\
\text { vistos, hoje em dia, quase como "coitados"." (B2) }\end{array}$} \\
\hline & Bauru & B2, B29 & \\
\hline & Presidente Prudente & PP10, PP12, PP33 & \\
\hline & S. J. do Rio Preto & - & \\
\hline \multirow{4}{*}{$\begin{array}{l}\text { III - Outros motivos ou } \\
\text { não responderam }\end{array}$} & Araraquara & A16, A25 & \multirow{4}{*}{$\begin{array}{l}\text { "Como uma profissão dificil de exercer por conta do desinte- } \\
\text { resse da maioria dos alunos." (B20) } \\
\text { "Apenas uma pessoa que tem por obrigação simplesmente } \\
\text { aprovar pessoas mesmo que inaptas para conviver em ambien- } \\
\text { tes profissionais. "(PP30) }\end{array}$} \\
\hline & Bauru & B15, B20 & \\
\hline & Presidente Prudente & PP18, PP25, PP30 & \\
\hline & S. J. do Rio Preto & - & \\
\hline
\end{tabular}

mais de $75 \%$ dos alunos que optaram por essa alternativa. O campus de Bauru é o que apresentou o maior número de licenciandos que acham o salário reajustado bom para o início da carreira, com mais de $26 \%$ dos respondentes. Esses dados se relacionam com a preferência de grande parte dos estudantes de atuarem como professores no ES e/ou ET e não na EB.

A análise dos dados do Quadro 2 acerca das visões dos ingressantes sobre o trabalho docente concorda com os resultados apresentados na Figura 6 no sentido de que o ofício do professor está muito mais relacionado a valores altruístas e à recompensa afetiva pelo bem ao próximo, em detrimento do status profissional e das condições salariais e de carreira. Essas visões são corroboradas justamente pelas percepções dos mesmos ingressantes sobre como a sociedade concebe o trabalho dos professores (Quadro 3) e a percepção de seus próprios pais. Uma vez que social e financeiramente o ofício docente é desvalorizado, sua atratividade se daria essencialmente em função do sentido de missão e possibilidade romântica de transformação da sociedade por meio da atuação heroica como professor, sendo que grande parte dos próprios ingressantes não consideram o piso salarial legal da profissão razoável. Esse fato reforça a motivação dos licenciandos para o ingresso na carreira por fatores fortemente intrínsecos.

De fato, algumas notícias trazem em destaque o desprestígio salarial da profissão docente..$^{33,34}$ A partir de dados coletados em pesquisas realizadas, as notícias apontam que o salário médio do professor equivale à metade do salário de um profissional com o mesmo nível de formação. Além disso, os noticiários alertam sobre o fato de mais de dez estados brasileiros não pagarem o piso mínimo determinado pelo MEC. Ademais, dados da Organização de Cooperação e de Desenvolvimento Econômico (OCDE) apontam que para ser professor no Brasil você deve trabalhar mais e ganhar menos do que em diversos outros países do mundo, o que acaba gerando desmotivação para a atuação profissional.

\section{CONCLUSÃO}

Portanto, no ano de 2013, a análise dos dados apresentados indica diversas aproximações e poucos afastamentos no perfil dos ingressantes dos cursos de LQ da Unesp que, com pequenas diferenças, é formado por grande parte dos alunos entre 17 e 19 anos, que não trabalham, oriundos da rede pública de ensino, de famílias cujos pais não possuem ES e com NSE intermediário. Ademais, a maior parte dos ingressantes era do sexo feminino. Os dados da Unesp concordam tanto com os obtidos no trabalho de Gatti e colaboradores, ${ }^{8}$ no qual o perfil socioeconômico daqueles que escolhem o magistério, em sua maioria, é formado por estudantes de classes econômicas menos abastadas, quanto com os dados do Exame Nacional do Ensino Médio, ${ }^{35}$ segundo os quais os licenciandos são alunos provenientes do sistema público de ensino. No tocante à diversidade étnica $\mathrm{e}$ racial, a maior parte dos ingressantes se autodeclara de cor branca, com baixo percentual de pardos e negros. Esse quadro se repete em vários outros cursos e em várias outras universidades. Vale sublinhar que a Unesp vem implantando gradativamente políticas de reservas de vagas e, por isso, seria interessante acompanhar o comportamento desse cenário nos próximos anos.

Em que pese o fato de terem prestado outros vestibulares, a maioria dos estudantes escolheu um curso da Unesp como primeira opção, por ter interesse na grande área do conhecimento e pela reputação e prestígio da universidade, por suas próprias opiniões e pretensões profissionais e, no geral, sabendo a diferença entre um bacharel e um licenciado. Considerando esses aspectos, é possível afirmar que o grupo de alunos investigado possuía motivações predominantemente 
intrínsecas e não motivações extrínsecas. Esse resultado é oposto ao encontrado por Sá e Santos para o curso de LQ da Bahia ${ }^{5}$, no qual os estudantes ingressaram principalmente por falta de outras oportunidades, ou seja, por fatores extrínsecos. O único afastamento identificado foi no curso de S. J. do Rio Preto em que a maioria, a despeito de ter optado em cursar a modalidade de licenciatura e não a de bacharelado, afirmou que o curso de LQ não havia sido a primeira opção no exame vestibular. Dado bastante preocupante que revela a questão de, muitas vezes, a escolha da profissão docente ser feita em função de ser a que se apresenta a mais viável no momento para os estudantes, com possibilidade de emprego imediato.

Ao contrário de diversos outros estudos, ${ }^{3-5}$ grande parte dos estudantes pesquisados declarou que a opção pela LQ se deu, no geral, por quererem ser professores. Contudo, apesar de ter uma percepção positiva e possuir a pretensão de exercer a profissão docente, a maior parte dos licenciandos não vislumbra a atuação necessariamente na EB em função de seu baixo status sociocultural e da projeção de condições difíceis de desenvolvimento do trabalho e, inclusive, considera que o baixo valor do piso salarial nacional definido em lei é um fator desestimulante para uma possível atuação.

Se, no geral, os estudantes que ascendem ao ES público e ingressam nos cursos de licenciatura não anseiam em atuar como professores da EB, os indícios de "apagão docente no EM", sobretudo nas áreas de ciências exatas e da natureza, apontado pelo relatório produzido em 2007 pela Comissão Especial instituída no âmbito da Câmara de Educação Básica, ${ }^{9}$ começam a se concretizar em nosso país. Essa falta de interesse pela profissão de professor da EB se torna ainda mais preocupante quando confrontada com os dados divulgados, em 2015, no relatório da OCDE, por meio do Programa Internacional de Avaliação de Estudantes (PISA - sigla em inglês - Programme for International Student Assessment), em que nenhum dos jovens brasileiros de 15 anos pesquisados afirmaram ter a intenção de serem professores da rede básica. Adicionalmente, os resultados dos relatórios de 2005 e 2006 da OCDE, que indicavam a escassez de docentes nos países componentes da organização, mostram que, no Brasil, são apresentadas evidências de que o número de aposentadorias tende a superar o número de formandos nos próximos anos, haja vista que cerca de $40 \%$ estão mais próximos da aposentadoria que do início de carreira. ${ }^{8}$ Esse cenário reclama extrema atenção por parte de nossos governantes e por pesquisadores da área, pois se o quadro atual não se reverter, em poucos anos podemos não ter mais professores com formação específica em nível superior para lecionarem na EB.

Para os quatro campi da Unesp foram identificadas visões romantizadas, vocacionais e altruístas acerca do trabalho docente, em que as recompensas afetivas e idealistas derivadas da atuação têm mais importância do que a valorização profissional, financeira e social. Inclusive os fatores altruístas, vocacionais e de realização pessoal foram os de maior incidência nas respostas dos ingressantes sobre os motivos para serem professores.

Como efeito, foi possível constatar que, no que tange à atratividade da carreira docente, as motivações dos ingressantes nos cursos de LQ da Unesp, no ano de 2013, inserem-se no campo dos fatores intrínsecos, com pequenas motivações inseridas em fatores extrínsecos, como perspectiva de incremento de renda e no NSE, taxa de retorno e status relacionado à profissão. Esse fato associado às diversas oportunidades oferecidas por renomadas instituições de pesquisa na área específica de Química, tais como bolsas de iniciação científica, estágios em indústrias químicas da região e possibilidade de ingresso em programa de pós-graduação, pode influenciar consideravelmente durante os cinco anos de graduação desses estudantes. Cabe destacar que os PPC das licenciaturas de todos os campi da Unesp preveem a possibilidade de exercício das atividades de um bacharel em Química mesmo para os licenciandos. Inclusive nos campi em que há a opção, um dos fatores expressivos de motivação para ingresso no curso foi justamente a possibilidade de dupla habilitação (bacharelado e licenciatura).

Como ressaltado por Lippe e Bastos, ${ }^{36}$ os cursos de formação inicial de professores são tratados de uma maneira muito "acadêmica", em que as disciplinas específicas são sobrepostas às disciplinas pedagógicas, ocasionando uma série de deficiências na formação do profissional e também na compreensão dos licenciandos quanto aos saberes necessários à profissão de professor. Diante de tais deficiências os professores em formação, ao iniciarem seus estágios supervisionados e lidarem com uma realidade do ofício bastante difícil e com diversas dificuldades, podem não saber enfrentá-las, causando a sensação de que as disciplinas pedagógicas de nada servem para sua formação e/ou que a realidade cotidiana das escolas da EB é inamovível, contribuindo, assim, para o desinteresse pelo magistério. ${ }^{36}$ Adicionalmente, os estudantes passam a conhecer melhor as condições de elevadas cargas horárias de trabalho, com atuação em diversas escolas com turnos variados, recorrentes na vida de diversos professores com o intuito de melhores condições salariais.

Considerando que as motivações se relacionam com o autoconceito, a identificação com a profissão, à maturidade e aos valores pessoais, ${ }^{3-7}$ todos os fatores anteriores associados ao próprio amadurecimento desses estudantes e às expectativas próprias de formandos acerca do futuro profissional, das projeções de estabilidade financeira e crescimento profissional, podem ser elementos potencializadores pela opção de não atuarem como professores de Química na EB, sobretudo, na rede pública de ensino.

Diante do cenário de possível "apagão docente no Ensino Médio", resta-nos a constatação de que uma política pública educacional que promova uma verdadeira e efetiva valorização e consolidação da profissão docente se faz premente. Profissão com um plano de carreira atrativo financeiramente e com condições de trabalho minimamente adequadas, para que possa atrair cada vez mais estudantes, menos em função de valores estritamente altruístas intrínsecos do que em função de vislumbrar seguir uma carreira reconhecida e valorizada social e financeiramente.

Com efeito, cabe sublinhar que, nesse processo de consolidação da profissão docente, as IES ocupam posição fulcral, uma vez que atuam de modo mais agudo na formação inicial de professores, podendo, como mostrado por Sá e Santos, ${ }^{5}$ influenciar significativamente na constituição das identidades docentes dos licenciandos, em especial os formadores ligados ao ensino de química, o que pode estimulá-los a ingressarem na carreira docente. Como corolário, os cursos de licenciatura das IES públicas têm grande responsabilidade social no que diz respeito à possibilidade da formação de futuros profissionais com uma concepção mais adequada acerca do trabalho docente enquanto ofício feito de saberes profissionais, ${ }^{37}$ bem como pelo compromisso social e engajamento político pela reivindicação do status profissional ao ofício de professor, que implica em seu reconhecimento social e econômico.

\section{REFERÊNCIAS}

1. http://download.inep.gov.br/educacao_superior/censo_superior/ documentos/2015/notas_sobre_o_censo_da_educacao_superior_2014. pdf, acessada em novembro de 2017.

2. http://www.planalto.gov.br/ccivil_03/leis/L9394.htm, acessada em novembro de 2017.

3. Damasceno, D.; Godinho, M. S.; Soares, M. H. F. B.; De Oliveira, A. E. A.; Quim Nova 2011, 34, 1666.

4. Milaré, T.; Weinert, P. L.; Quim. Nova 2016, 39, 522.

5. Sá, C. S. S.; Santos, W. L. P.; Quim. Nova 2016, 39, 104.

6. Mazzetto, S. E.; Bravo, C. C.; Carneiro, S.; Quim. Nova 2002, 25, 1204. 
7. Santos, B. S.; Antunes, D. D.; Revista Educação 2007, 1(61), 149.

8. Gatti, B. A.; Tartuce, G. L. B. P.; Nunes, M. M. R.; Almeida, P. C. A. (coord.); In Estudos e Pesquisas Educacionais, $n^{\circ} 1$, Fundação Victor Civita: São Paulo, 2010, pp. 139-210.

9. http://portal.mec.gov.br/cne/arquivos/pdf/escassez1.pdf, acessada em novembro de 2017.

10. Agostini, G.; Sgarbosa, E. C.; Bego, A. M.; Oliveira, O. M. M. F.; Anais do XVII Encontro Nacional de Ensino de Química, Ouro Preto, Brasil, 2014.

11. Agostini, G.; Sgarbosa, E. C.; Marques, J. A. C.; Silva, L. V.; Bego, A. M.; Anais do XIII Evento de Educação em Química, Araraquara, Brasil, 2015.

12. Bego, A. M.; Agostini, G.; Sgarbosa, E. C.; Silva L. V.; Marques, J. A. C.; Anais do III Congresso Nacional de Formação de Professores e do XIII Congresso Estadual Paulista sobre Formação de Educadores, São Paulo, Brasil, 2016.

13. Silva, L. V.; Agostini, G.; Sgarbosa, E. C.; Marques, J. A. C.; Bego, A. M.; Anais do V Congresso Brasileiro de Educação, Bauru, Brasil, 2015.

14. Sgarbosa, E. C.; Agostini, G.; Marques, J. A. C.; Silva, L. V.; Julio, W. R.; Bego, A. M.; Oliveira, M. M. F. Anais do XII Evento de Educação em Química, Araraquara, Brasil, 2014.

15. http://www.iq.unesp.br/Home/graduacao/projeto-pedagogico-lic.pdf, acessada em novembro de 2017.

16. http://portal.mec.gov.br/cne/arquivos/pdf/rcp01_02.pdf, acessada em novembro de 2017.

17. http://www.fc.unesp.br/Home/Departamentos/quimica201/projetopolitico-pedagogico-quimica.pdf, acessada em novembro de 2017.

18. http://www.fct.unesp.br/Home/Graduacao/Quimica/projeto-pedagogico_ quimicafct_unesp.pdf, acessada em novembro de 2017.

19. http://www.ibilce.unesp.br/Home/Graduacao450/QuimicaAmbiental/ iii---projeto-pedagogico-quimica-unesp-sjrp-v0-p1-46.pdf, acessada em novembro de 2017.

20. Moreira, D. A.; O método fenomenológico na pesquisa, $1^{\text {a }}$ ed., Pioneira Thomson: São Paulo, 2002.

21. Bussab, W. O.; Morettin, P. A.; Estatística Básica, $6^{\text {a }}$ ed., Saraiva: São Paulo, 2009.
22. Bardin, L.; Análise de conteúdo, Edições 70: Lisboa, 2001.

23. Flick, U.; Desenho da pesquisa qualitativa, $1^{\mathrm{a}}$ ed., Bookman: Porto Alegre, 2009.

24. Francisco Jr., W. E.; Paternele, W. S.; Yamashita, M. A.; Quim. Nova Esc. 2009, 31, 113.

25. Montero, L.; A construção do conhecimento profissional docente, $1^{\mathrm{a}} \mathrm{ed}$., Editora Piaget: Porto Alegre, 2001

26. Tozzi, M. J.; Tozzi, A. R.; Anais do XXVIII Congresso Brasileiro de Educação em Engenharia, Fortaleza, Brasil, 2010.

27. Watanabe F. Y.; Francisco, C. A.; França, C. A.; Ogashawara, O. A.; Revista Eletrônica Engenharia Viva 2015, 1, 51.

28. Vianna, J. F.; Aydos, M. C.; Siqueira, O. S.; Quim. Nova 1997, 20, 213.

29. Rabelo, A. O.; Revista Lusófona de Educação 2010, 15, 163.

30. http://guiadoestudante.abril.com.br/universidades/unesp-tem-recordede-inscritos-para-o-vestibular-2016/, acessado em novembro de 2017.

31. Ludke, M.; Boing, L. A.; Educação \& Sociedade 2004, 25, 1159.

32. http://portal.mec.gov.br/index.php?option=com_content\&view=arti cle\&id=20191: piso-salarial-do-magisterio-sera-reajustado-em-832conforme-a-lei-valor-sera-de-r-1697\&catid=211\&Itemid=86, acessado em novembro de 2017.

33. http://g1.globo.com/bom-dia-brasil/noticia/2016/06/professor-comnivel-superior-ganha-metade-do-que-outros-graduados.html, acessada em novembro de 2017.

34. http://www.todospelaeducacao.org.br/educacao-na-midia/indice/30594/ no-brasil-salario-de-professor-e-metade-do-que-recebem-outrosprofissionais, acessada em novembro de 2017.

35. http://portal.inep.gov.br/artigo/-/asset_publisher/B4AQV9zFY7Bv/ content/inep-divulga-resultados-do-enem-2008/21206, acessada em novembro de 2017

36. Lippe, E. M. O.; Bastos, F.; Formação de professores e práticas pedagógicas no ensino de ciências, $1^{a}$ ed., Escrituras Editora: São Paulo, 2008, cap. 4.

37. Gauthier, C.; Martineau, S.; Desbiens, J. F.; Malo, A.; Simard, D.; Por uma teoria da pedagogia: pesquisas contemporâneas sobre o saber docente, 1ª ed., Unijuí: Ijuí, 1998. 